\title{
N-Acetyl Aspartate Measurement
}

National Cancer Institute

\section{Source}

National Cancer Institute. N-Acetyl Aspartate Measurement. NCI Thesaurus. Code C156561.

The determination of the amount of $\mathrm{N}$-acetyl aspartate in a biological specimen. 